(1)

CrossMark

\title{
Desquamative interstitial pneumonia: a systematic review of its features and outcomes
}

\author{
Merel E. Hellemons ${ }^{1,8,9}$, Catharina C. Moor ${ }^{1,8,9}$, Jan von der Thüsen ${ }^{2,8}$, \\ Mariska Rossius ${ }^{3,8}$, Arlette Odink ${ }^{3,8}$, Laila Haugen Thorgersen ${ }^{4}$, \\ Johny Verschakelen ${ }^{5,8}$, Wim Wuyts (10,8,10, Marlies S. Wijsenbeek ${ }^{1,8,10}$ and \\ Elisabeth Bendstrup $7,8,10$
}

Affiliations: ${ }^{1}$ Dept of Interstitial Lung Disease, Erasmus Medical Center, Rotterdam, The Netherlands. ${ }^{2}$ Dept of Pathology, Erasmus Medical Center, Rotterdam, The Netherlands. ${ }^{3}$ Dept of Radiology and Nuclear Medicine, Erasmus Medical Center, Rotterdam, The Netherlands. ${ }^{4}$ Dept of Respiratory Diseases, Nastved Hospital, Nastved, Denmark. ${ }^{5}$ Dept of Radiology, University Hospital Leuven, Leuven, Belgium. ${ }^{6}$ Unit of Interstitial Lung Disease, University Hospital Leuven, Leuven, Belgium. ${ }^{7}$ Dept of Respiratory Diseases and Allergy, Center for Rare Lung Diseases, Aarhus University Hospital, Aarhus, Denmark. ${ }^{8}$ This centre is a member of the European Reference Network for Rare Lung Diseases/Interstitial Lung Diseases (ERN-LUNG ILD). ${ }^{9}$ These authors share first authorship. ${ }^{10}$ These authors share senior authorship.

Correspondence: Marlies Wijsenbeek, Erasmus Medical Center Rotterdam, Dr. Molewaterplein 40, 3015 GD Rotterdam, The Netherlands. E-mail: m.wijsenbeek-lourensderasmusmc.nl

@ERSpublications

This systematic review is the most comprehensive collection of published cases of DIP to date and yields novel information about aetiology, clinical characteristics, radiology and pathology features, treatment and outcomes. http://bit.ly/394YRPv

Cite this article as: Hellemons ME, Moor CC, von der Thüsen J, et al. Desquamative interstitial pneumonia: a systematic review of its features and outcomes. Eur Respir Rev 2020; 29: 190181 [https://doi. org/10.1183/16000617.0181-2019].

\section{ABSTRACT}

Background: Desquamative Interstitial Pneumonia (DIP) is a rare form of idiopathic interstitial pneumonia (IIP). Data on clinical features, aetiology, prognosis and effect of treatment strategies are limited. We aimed to collect all published cases to better characterise DIP.

Methods: A systematic literature search was performed for all original cases of adult patients with histopathologically-confirmed DIP. Individual patient data were extracted and summarised.

Results: We included 68 individual cases and 13 case series reporting on 294 cases. Most common presenting symptoms were dyspnoea and cough. Pulmonary function showed a restrictive pattern (71\%) with decreased diffusion capacity. We found a high incidence (81\%) of ever smoking in patients with DIP and $22 \%$ of patients had other (occupational) exposures. Characteristic features on high-resolution computed tomography (HRCT) scan were bilateral ground-glass opacities with lower lobe predominance (92\%). Treatment and duration of treatment widely varied. Initial response to treatment was generally good, but definitely not uniformly so. A significant proportion of patients died ( $25 \%$ of individual cases) or experienced a relapse ( $18 \%$ of individual cases). Conclusion: DIP remains an uncommon disease, frequently but not always related to smoking or other exposures. Furthermore, DIP behaves as a progressive disease more often than generally thought, possibly associated with different underlying aetiology.

This article has an editorial commentary https://doi.org/10.1183/16000617.0183-2020

This article has supplementary material available from err.ersjournals.com

This trial is registered at Prospero with registry number CRD 42019136304

Provenance: Submitted article, peer reviewed

Received: 13 Dec 2019 | Accepted after revision: 29 Jan 2020

Copyright $\odot$ ERS 2020. This article is open access and distributed under the terms of the Creative Commons Attribution Non-Commercial Licence 4.0. 


\section{Introduction}

Desquamative interstitial pneumonia (DIP) is a rare form of idiopathic interstitial pneumonia (IIP), as classified by international multidisciplinary consensus classification guidelines [1]. The term DIP originates from the original studies in the 1960s, when it was thought that the histologically observed alveolar infiltrates stemmed from alveolar epithelial cell desquamation [2]. Later, it was shown that instead of desquamation, the infiltrates represent alveolar filling with pigmented macrophages. Nonetheless, the European Respiratory Society (ERS) and the American Thoracic Society (ATS) have preserved the term DIP since it is a rare entity; however, the term alveolar macrophage pneumonia was considered at times [3, 4].

DIP is usually associated with exposure to tobacco smoke; however, the association between smoking and DIP is less robust than with several other smoking-related lung disorders, as a substantial proportion of patients diagnosed with DIP (9-42\%) were never smokers in small series of patients. Other inhaled exposures are indicated as potential culprits and in some cases are highly probable, but little is known regarding precise aetiology or dose response relationships. Occupational exposure, drug reactions and autoimmune diseases, as well as passive smoking, have also been linked to the disease, although not as consistently as tobacco exposure [4].

A diagnosis of DIP cannot be reliably established based on clinical and radiological features alone and ideally requires a (surgical) lung biopsy. The histomorphology is characterised by the diffuse accumulation of numerous pigmented macrophages within most of the distal airspace of the lung and, sometimes, an admixture of eosinophils and/or giant cells. Even in histology, it is difficult to discriminate DIP from disorders in the same spectrum involving pigmented macrophages, such as respiratory bronchiolitis interstitial lung disease (RB-ILD).

According to the current guidelines, diagnosis of DIP should be established in a multidisciplinary team (MDT) meeting, integrating medical history and radiology, as well as bronchoalveolar lavage (BAL) and pathology findings. However, good consensus criteria are still lacking due to the lack of knowledge of this disease, likely leading to under-recognition of DIP in clinical practice [1]. Series in the literature are limited in number and small in size. Data on the clinical features and aetiology of DIP are limited and even less is known with respect to prognosis and the effect of treatment strategies.

The aim of this study is to systematically collect all cases and case studies published to date, in order to more precisely characterise the disease regarding clinical characteristics, exposures and radiology, as well as pathology features, treatment strategies and outcomes.

\section{Methods}

Search strategy

A systematic literature search was performed in six online databases (PubMed, Embase, Medline, Web of Science, Cochrane and Google Scholar), for articles between 1965 and February 2019. For this search, the medical subject heading (MeSH) terms "desquamative interstitial pneumonia", "desquamative interstitial pneumonitis" and "DIP" were used. Additional articles were identified through the reference lists of the already identified papers. All original case reports and case series of adult patients with histopathologically-confirmed DIP were included in this review. However, articles were restricted to those published in the English language and were excluded if data extraction was not possible due to limited available information about individual cases (supplementary figure 1). Conference abstracts were also excluded, as not enough data could be extracted. This systematic review was pre-registered in the Prospero registry for systematic reviews, with registration number CRD42019136304.

\section{Outcomes}

All included articles were assessed according to a pre-specified scoring form (for details, see the Prospero database). Cases and case series were screened for clinical data, such as symptoms, physical examinations, comorbidities, smoking status and other exposures, treatment of DIP and outcomes. Furthermore, radiological and histopathological parameters were evaluated.

\section{Data analysis}

Available data were extracted and then collected and analysed using Microsoft Excel 2010 (Microsoft Corp., Redmond, WA, USA). Not all parameters were available in all reports. Data are presented as $\mathrm{n} / \mathrm{n}$ (\%) and summarised as $\mathrm{n} / \mathrm{n}$ (\%) of available data. For statistical analysis, outcomes were categorised as favourable (remission, improvement or stabilisation) versus unfavourable (deterioration, relapse, death or transplantation). Differences in outcomes between groups of patients were evaluated with Chi-squared tests using SPSS software, version 25.0 (IBM Corp., Armonk, NY, USA). 


\section{Results}

The systematic search retrieved a total of 961 articles (supplementary figure 1), which were screened for eligibility by two authors (M.E. Hellemons and C.C. Moor). In case of disagreement, articles were discussed with a third author (M.S. Wijsenbeek) until consensus was reached. After exclusion of irrelevant articles this search resulted in the inclusion of 75 studies in the analysis [5-66]. Of these 75 studies, 62 were case reports reporting on 68 cases and 13 were patient series reporting on three or more patients each, with a total of 294 cases [2, 67-78]. There were a number of case series from which individual patient data could not be reliably extracted and these series were excluded from this review (supplementary figure 1).

\section{Clinical characteristics}

In the 362 published cases that we collected, 224 patients were male (62\%) (table 1). The mean age at presentation was 40-50 years, but ranged from 16-79 years. Based on reported clinical data from 147 cases, the vast majority of patients presented with exertional dyspnoea (86\%) and cough (65\%) (table 1). Other symptoms included fever (31\%), chest pain (19\%), fatigue (22\%) and anorexia or weight loss (13\%). A few patients mentioned symptoms such as arthralgia $(n=3)$, Raynaud's phenomenon $(n=3)$, abdominal pain $(n=3)$ and haemoptysis $(n=2)$. The average duration of complaints prior to diagnosis was 13 months and ranged from 1 week to 10 years. A minority of patients (8\%) had no complaints at all; diagnosis of these patients was made after incidental findings on chest radiograph or computed tomography (CT) images. Upon physical examination, crackles were heard in $64 \%$ of patients and clubbing was present in $33 \%$. Physical examination was unremarkable in approximately one fifth of patients (19\%).

\section{Pulmonary function tests}

Pulmonary function tests (PFTs) at diagnosis most commonly showed a restrictive pattern with decreased diffusion capacity (71\% of cases). Less commonly, an obstructive or a combined restrictive and obstructive pattern was shown, especially in heavy smokers. Pulmonary function was completely normal in $8-20 \%$ of cases.

\section{Bronchoscopy}

Data on cellularity of BAL in DIP was scarce (it was only available in eight out of the 68 cases and in two series) $[7,12,14,18,21,24,46,48,77,78]$. BAL generally demonstrated high numbers of pigmented macrophages, but with a considerable range. The largest number of BAL procedures in DIP $(n=9)$ was reported by BALOIRA et al. [77]. The number of pigmented macrophages in this series ranged from 55-98\%.

In a series of BAL procedures in interstitial lung disease (ILD), it was reported that eosinophil counts were generally low in DIP (mean 5-10\%) but differed significantly between patients [79]. In the series by BALOIRA et al. [77], eosinophils were above $10 \%$ in two out of nine patients. In the series from KaWABATA et al. [78] higher eosinophil counts were shown (on average 17\%), with a range from $0-62 \%$ in 26 patients. Transbronchial biopsies usually failed to establish a diagnosis of DIP and, in the series from RYU et al. [75], this procedure was performed seven times without diagnostic results. In the series from BALOIRA et al. [77], transbronchial biopsies suggested DIP in three out of nine cases. All cases were confirmed with a surgical lung biopsy.

\section{Aetiological factors \\ Smoking}

Smoking is the most well known contributor to DIP, although the correlation is not as strong as seen with other smoking-related ILDs such as Langerhans' cell histiocytosis and RB-ILD [80]. In the published studies, smoking status was reported in 161 patients (44\%); however, in the earliest reports especially, smoking status was often not mentioned. The earliest publication of a potential relationship with smoking exposure dates from 1987, 22 years after the entity of DIP was first described [81] and most reports after 1990 mention smoking status. We found a high incidence (81\%) of ever smoking in patients with DIP, of whom the majority $(n=113)$ were active smokers at the time of diagnosis. Only 17 patients were former smokers and a considerable proportion of patients had never smoked (19\%) (table 2).

\section{Other exposures}

Other exposures were mentioned as possible causes of DIP in 22 out of the 68 individual cases (34\%). Of these 22 cases, eight patients were also current smokers. Five series reported on exposures and 11 out of 84 patients (13\%) had other exposures. Most exposures were occupation related and caused by inhalation of organic or inorganic dust. Reported professions possibly associated with DIP were farmer $(\mathrm{n}=4)$, metal worker $(n=4)$, auto mechanic $(n=1)$, fire fighter $(n=1)$, mine worker $(n=1)$, rock blaster $(n=1)$ and painter $(n=1)$. Other patients worked in a potato chip factory $(n=1)$, a wood chip factory $(n=1)$, had exposure to 
TABLE 1 Patient demographics and clinical characteristics

\begin{tabular}{|c|c|c|c|c|c|c|c|c|c|c|c|c|c|c|c|}
\hline Study (first author) & Liebow & Gaensler & Tubbs & Valdivia & Carrington & Yousem & Hartman & Akira & Travis & Ryu & Craig & Baloira & Kawabata & Individual cases & Total \\
\hline Country of study & USA & USA & USA & USA & USA & USA & Canada & Japan & USA & USA & UK & Spain & Japan & Various & - \\
\hline Year published & 1965 & 1966 & 1977 & 1977 & 1978 & 1989 & 1993 & 1997 & 2000 & 2004 & 2004 & 2007 & 2012 & $1966-2019$ & - \\
\hline Patients & 18 & 12 & 26 & 30 & 40 & 36 & 22 & 8 & 16 & 23 & 20 & 12 & 31 & 68 & 362 \\
\hline Male gender & $10(56)$ & $7(58)$ & $17(65)$ & - & $28(70)$ & 26 (72) & $6(22)$ & $7(88)$ & $7(44)$ & $11(48)$ & $12(60)$ & $12(100)$ & $29(96)$ & $52(76)$ & $224(62)$ \\
\hline Age years & $42(16-61)$ & $39(17-65)$ & $52(24-75)$ & - & $42 \pm 12$ & $42(17-67)$ & $43(22-71)$ & $56 \pm 8$ & 42 (27-79) & $46 \pm 10$ & $43(27-74)$ & $50 \pm 16$ & $55 \pm 13$ & $45 \pm 14$ & - \\
\hline Non-productive cough & 14 (78) & - & $17(65)$ & - & - & - & - & - & - & $10(43)$ & - & $9(75)$ & - & $46(68)$ & $96 / 147(65)$ \\
\hline Exertional dyspnoea & $18(100)$ & - & $23(88)$ & - & - & - & - & - & - & $20(87)$ & - & $7(58)$ & - & $58(85)$ & $127 / 147(86)$ \\
\hline Chest pain & $9(50)$ & - & $1(4)$ & - & - & - & - & - & - & $4(17)$ & - & $0(0)$ & - & $12(18)$ & $26 / 147$ (19) \\
\hline Fever & - & - & - & - & - & - & - & - & - & - & - & - & - & $21(31)$ & $21 / 68(31)$ \\
\hline Fatigue & - & - & - & - & - & - & - & - & - & - & - & - & - & 15 (22) & $15 / 68$ (22) \\
\hline Anorexia/weight loss & $6(33)$ & - & $1(4)$ & - & - & - & - & - & - & - & - & - & - & $8(12)$ & $15 / 112(13)$ \\
\hline $\begin{array}{l}\text { Symptoms prior to } \\
\text { presentation months }\end{array}$ & $17(2-72)$ & - & - & - & - & - & - & - & - & - & - & - & - & $14(0.25-120)$ & $13(1-120)$ \\
\hline $\begin{array}{l}\text { No symptoms } \\
\text { (incidental finding) }\end{array}$ & - & - & $1(4)$ & - & - & - & - & - & - & $1(4)$ & - & 1 (8) & - & $5(7)$ & $8 / 129(6)$ \\
\hline $\begin{array}{l}\text { Normal physical } \\
\text { examination }\end{array}$ & - & - & - & - & - & - & - & - & - & - & - & - & - & $13(19)$ & $13 / 68(19)$ \\
\hline Crackles & - & - & $17(65)$ & - & - & - & - & - & - & $13(57)$ & - & $11(92)$ & - & 41 (72) & $82 / 129(64)$ \\
\hline Clubbing & $5(28)$ & - & $12(46)$ & - & - & - & - & - & - & $6(26)$ & - & $7(58)$ & - & 18 (32) & 48/147 (33) \\
\hline
\end{tabular}

Data are presented as $\mathrm{n}, \mathrm{n}(\%), \mathrm{n} / \mathrm{n}(\%)$, mean $\pm \mathrm{SD}$, or mean (range). Available data from case series and individual cases are presented. Totals data are summarised as percentages of available data. 
TABLE 2 Patient smoking history

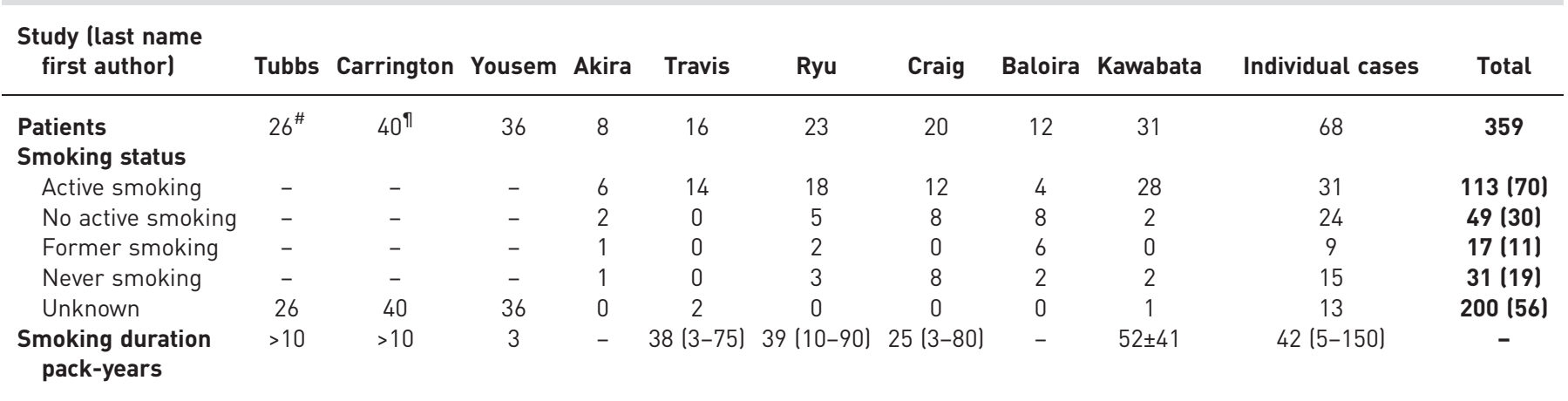

Data are presented as $\mathrm{n}, \mathrm{n}(\%)$, mean $\pm \mathrm{SD}$, or mean (range). Available data on smoking exposition in case series and individual cases are presented. Totals data are summarised as percentages of available data. ${ }^{\#}$ : $58 \%$ of patients smoked more than 10 pack-years. The proportion of ever smoking or active smoking patients is unknown. " : $90 \%$ of patients smoked more than 10 pack-years. The proportion of ever smoking or active smoking patients is unknown.

asbestos $(n=6)$, beryllium $(n=1)$, hairspray $(n=3)$, waterproofing spray $(n=1)$, diesel fumes $(n=1)$, fire extinguishing powder $(n=1)$, plastic fumes $(n=1)$ or insecticides $(n=2)$. Finally, in one case, a recent tattoo was proposed as a possible trigger for development of DIP [14]. An unequivocal causal relationship between exposure and the occurrence of DIP could not be established in any of these cases, however, nor was there any information on the level of exposure.

\section{Comorbidities and medication}

A number of patients had auto-immune diseases, such as systemic sclerosis $(n=3)$, rheumatoid arthritis $(n=3)$ and systemic lupus erythematosus $(n=2)$. These and other potentially related comorbidities can be found in supplementary table 1 . In the case series, a significant proportion of patients also presented with positive auto-antibodies, but did not meet diagnostic criteria for a systemic disease (supplementary table 1). In two cases a possible association with chronic monomyelocytic leukaemia was suggested, although the relationship to DIP could not be elucidated [29]. Remarkably, DIP was also linked with infectious diseases such as hepatitis $(n=3)$ and cytomegalovirus $(n=1)[12,15,16,65]$. In these cases it was not always clear whether the disease itself or its pharmacological treatment (interferon/ribavirin) might have caused DIP. Furthermore, nitrofurantoin $(n=2)$, sirolimus $(n=1)$ and sulfasalazine $(n=1)$ were mentioned as potential triggers [33, 47,65]. Again, causality could not be established in any of these cases with certainty.

\section{Idiopathic DIP}

Of the 15 individual cases without smoking history, five had other potential triggering exposures. Of the remaining 10 patients, three had positive antinuclear antibodies (ANA) and one of these three also had a positive rheumatoid factor. Whereas in the seropositive cases it remains unclear whether the underlying auto-immunity was a cause of DIP, at least seven cases remain truly idiopathic. In the series from CRAIG et al. [76], two out of the eight never smokers had occupational exposure and two had a positive rheumatoid factor. Again this leaves $50 \%$ of the cases without any potential underlying trigger. In other series, data about idiopathic DIP could not be extracted.

\section{Radiology}

In the oldest case reports only radiographs were described, as CT scans were not yet available. As such, data from 217 radiographs and 114 high-resolution computed tomography (HRCT) chest scans were presented in the published cases. The vast majority of the reported radiographs (90\%) demonstrated a bilateral interstitial pattern, mainly with basal predominance (78\%). However, in a small percentage of cases $(10 \%)$ the radiograph showed no abnormalities (supplementary table 2).

All HRCT scans showed interstitial abnormalities. Radiologically, DIP is typically characterised by the presence of bilateral ground-glass opacities located in the basal parts of the lung (seen in $92 \%$ of patients) and is often associated with fine reticulation. A typical case is shown in figure 1. Other reported HRCT features were irregular reticulation, traction bronchiectasis and cysts. The cystic changes described in the articles ranged from minor cystic lesions to honeycombing, making interpretation difficult. Nonetheless, it is notable that in a significant number of cases there were not only ground-glass opacities but also clear signs of fibrosis, with architectural distortion, traction bronchiectasis and honeycombing. 

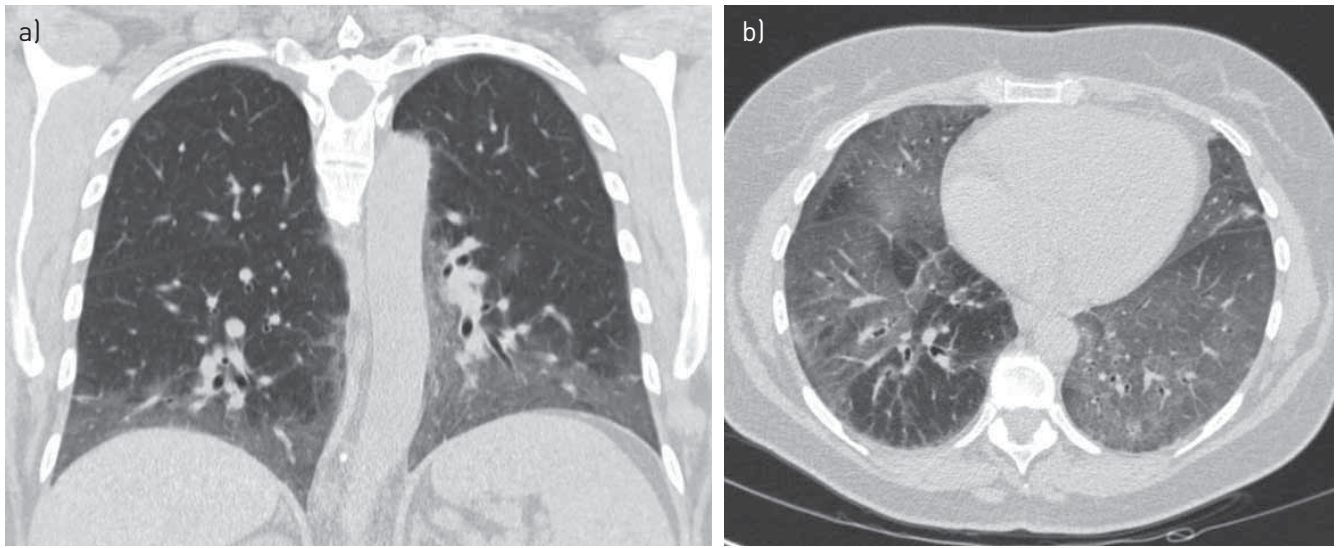

FIGURE 1 Typical example of high-resolution computed tomography (HRCT) findings in desquamative interstitial pneumonia (DIP). Coronal a) and axial b) computed tomography (CT) slices show bilateral basal and peripheral ground-glass opacity. Some superimposed fine linear opacities are also seen, especially on the left side (coronal slice a)), corresponding with thickened inter- and intralobular septa.

\section{Pathology features}

All cases in this review were confirmed by pathology. Nonetheless, specific pathological features were often not mentioned. Histopathologically, DIP is characterised by diffuse filling of alveolar spaces with (pigmented) macrophages, as well as diffuse widening of alveolar septa, suggestive of a fibrotic non-specific interstitial pneumonia (NSIP) pattern. Reactive pneumocytic epithelial cells and sporadic eosinophils can also be seen. A typical case is shown in figure 2.

Descriptive pathology data could be extracted in two out of 13 case series and in $93 \%$ of individual cases. Filling of alveoli with macrophages is considered to be the main histological hallmark of DIP and was described in all published cases. These macrophages often contain a variable amount of diffuse light brown pigment. However, in many included cases pigmentation of macrophages was not discussed in detail. Other frequently described histological features were increased septal thickening, interstitial inflammation and the presence of lymph follicles and eosinophils (supplementary table 3). Furthermore, interstitial fibrosis, fibrosing pleuritis and cuboidal cell metaplasia have been mentioned in a number of patients.

\section{Treatment}

As an initial treatment strategy, removal of the suspected culprit exposure, either alone or combined with steroids, was only mentioned in 27 cases (23\%). It is likely that smoking cessation combined with medical interventions was the most prevalent strategy, but this was not always mentioned.

Treatment was initiated in $91 \%$ of cases and, in the majority, this was treatment with corticosteroids (most frequently prednisolone, less commonly intravenous or oral methylprednisolone). Dosage of steroids was very diverse and ranged between $15 \mathrm{mg} \cdot \mathrm{day}^{-1}$ (prednisolone) to $1 \mathrm{~g} \cdot \mathrm{day}^{-1}$ (methylprednisolone). Likewise, the duration of treatment with steroids was extremely diverse, ranging from 2 weeks to several months and maintenance treatment.
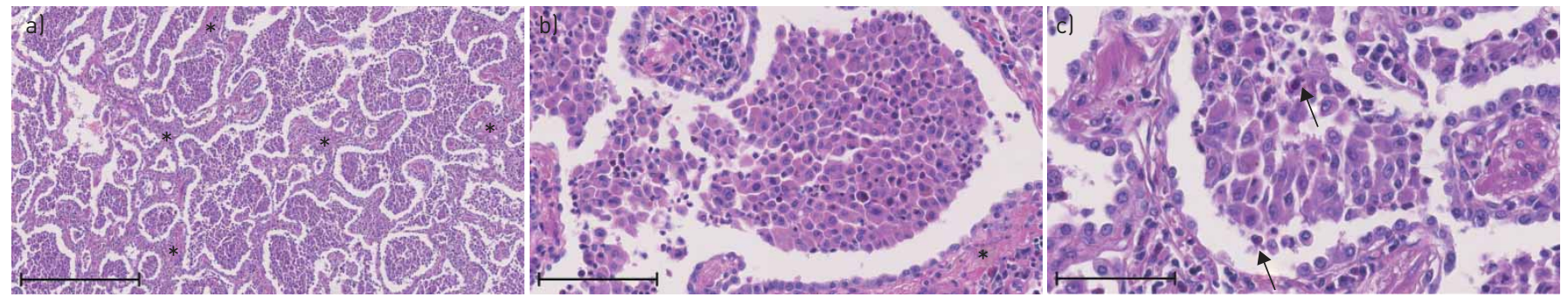

FIGURE 2 Typical examples of histopathological findings in desquamative interstitial pneumonia (DIP) using a hematoxylin-eosin stain. The low-power view a) demonstrates diffuse filling of alveolar spaces with macrophages, as well as diffuse widening of alveolar septa (asterisks) suggestive of a fibrotic non-specific interstitial pneumonia (NSIP) pattern. Scale bar=1 mm. The medium-power view b) shows complete filling of a single alveolus with slightly pigmented macrophages (asterisk). Scale bar=0.1 $\mathrm{mm}$. The high-power view $\mathrm{c}$ ) shows reactive pneumocytic epithelial cells, alveolar filling with macrophages and sporadic eosinophils (arrows). Scale bar $=0.05 \mathrm{~mm}$. 
Other treatments that were given with lower frequency included: antibiotics (such as clarithromycin), azathioprine, ribavirin, chloroquine and cyclophosphamide. In most but not all cases these treatments were instituted after failure of corticosteroids or as a steroid-sparing strategy.

\section{Treatment response}

Data on specific responses to smoking cessation or removal of another culprit exposure were not available. Assessing overall treatment response amongst all studies, initial response to treatment was generally good, but this was definitely not uniform (table 3). Of 60 cases reporting on outcome, 38 had a good outcome $(63 \%)$ and five patients (8\%) were stable. However, 15 patients (25\%) died and two patients (3\%) underwent lung transplantation. In addition, at least $18 \%$ of cases experienced a relapse after cessation of treatment. In the series from CARRINGTON et al. [70], a treatment effect was suggested and prognosis seemed to improve with treatment. In untreated patients, $22 \%$ improved over a course of 6.8 years, $15 \%$ were stable and $62 \%$ worsened. However, in patients who were treated, $62 \%$ improved, $11 \%$ was stable and $27 \%$ worsened over a course of 3.1 years.

Looking at objective outcomes such as repeated PFTs only seven out of 39 cases with reported PFT data normalised (18\%), 15 improved (38\%), 10 stabilised (26\%) and seven deteriorated (18\%). There may be an underestimation of declining lung function, as patients who rapidly deteriorated or died frequently did not have repeated PFTs and follow-up was generally short or not reported.

Strikingly, when looking at the 55 individual cases with known smoking history and outcome, $70 \%$ of the cases with smoking history (28 out of 40 cases) had a good outcome (improvement or clinical stability) versus only $40 \%$ in the patients without smoking history (six out of 15 cases) ( $\mathrm{p}=0.04$ by Chi-squared test). Furthermore, women had a worse outcome compared with men as $41 \%$ of women (seven out of 17 cases) had a good outcome versus $71 \%$ of men (36 out of 51 cases) ( $\mathrm{p}=0.029)$. However, women were also more frequently never smokers (46\%) compared with men (21\%). Clubbing was not associated with worse prognosis $(\mathrm{p}=0.83)$ or fibrosis (reticulation) on HRCT scan $(\mathrm{p}=0.67)$. No association was found between fibrosis (reticulation) on HRCT scan and outcome $(\mathrm{p}=0.73)$, but numbers were small $(\mathrm{n}=29)$.

\section{Discussion}

To our knowledge, this retrospective series is the most comprehensive collection of published cases of DIP to date, stretching from the initial report of DIP in 1965 to this year. In total we found data on 362 cases, which were summarised in this review. For an uncommon disease, this review therefore presents the most complete overview of DIP to date, of its features and of its outcomes.

TABLE 3 Treatment strategies and outcomes

\begin{tabular}{|c|c|c|c|c|c|c|c|c|c|c|}
\hline Study (last name first author) & Tubbs & Carrington & Yousem & Akira & Travis & Ryu & Baloira & Kawabata & $\begin{array}{l}\text { Individual } \\
\text { cases }\end{array}$ & Total \\
\hline Treatment & - & $26 / 40(65)$ & - & - & - & $21 / 23(91)$ & $12 / 12(100)$ & $31 / 31(100)$ & ) $61 / 67$ (91) & $151 / 173(87)$ \\
\hline Prednisolone & - & - & - & - & - & $21 / 23(91)$ & $9 / 12(75)$ & $31 / 31(100)$ & ) $58 / 67(86)$ & $119 / 133(89)$ \\
\hline Other first/second line treatment & - & - & - & - & - & - & $3 / 12(25)$ & - & $12 / 67(18)$ & $15 / 79(19)$ \\
\hline Follow-up years & - & $3.1 \pm 2.8$ & $9(0.8-22)$ & $3.2 \pm 1.3$ & - & $3.1 \pm 3.7$ & $1.9(0.8-5.8)$ & 8.25 & - & - \\
\hline Stable & - & $3 / 26(11)$ & $3 / 25(12)$ & $3 / 6(50)$ & $12 / 18(67)$ & ) 12/19 (63) & $2 / 8(25)$ & - & $5 / 66$ (8) & $37 / 168(22)$ \\
\hline Worsened & $7 / 14$ (50) & ) $7 / 26$ (27) & $8 / 25$ (32) & $1 / 6$ (147) & $5 / 18$ (28) & $1 / 19$ (5) & $2 / 8$ (25) & $5 / 14(36)$ & - & $26 / 130(20)$ \\
\hline Death & - & - & - & - & $1 / 18(6)^{\#}$ & $5 / 19(25)^{9}$ & - & $1 / 31(3)$ & $14 / 66$ (22) & $21 / 134(16)$ \\
\hline Transplantation & - & - & - & - & - & - & - & - & 2/66 (3) & $2 / 66(3)$ \\
\hline Relapse & - & - & - & - & - & - & - & - & $12 / 62$ (18) & $12 / 62(18)$ \\
\hline \multicolumn{11}{|l|}{ PFT } \\
\hline
\end{tabular}

Data are presented as $\mathrm{n} / \mathrm{n}(\%)$, mean, mean $\pm \mathrm{SD}$, or mean (range). Available data from case series and individual cases are presented. Totals data are summarised as percentages of available data. PFT: pulmonary function test; CT: computed tomography. \#: patient committed suicide;

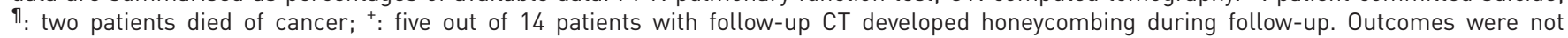
uniformly good as suggested by these data. 
As evidenced by the reported cases, DIP generally presents in the fifth decade of life and there is a slight male predominance. DIP has also been reported in children ( 41 articles in the literature search) but, as the aetiology is probably different (with mostly familial cases), we excluded paediatric cases in the current review. Most patients complain of exertional dyspnoea and dry cough and have had complaints for a considerable time prior to definitive diagnosis. Crackles are the most frequent remarkable finding at physical examination. Generally, pulmonary function shows a restrictive pattern with a decreased diffusion capacity and smoking is the most commonly related trigger. Radiologically, diffuse bilateral ground-glass abnormalities with lower lobe predominance are noted. Histologically, the disease is characterised by a diffuse intra-alveolar presence of pigmented macrophages, with a frequent admixture of a moderate number of eosinophils and a varying amount of interstitial fibrosis. Most patients are treated with steroids, with reasonable effects.

These general findings are in line with most individual reports on DIP; nonetheless, the itemised overview of reported clinical symptoms and other findings provides more precise insights into the spectrum of disease characteristics than those that have thus far been published based on individual small series of patients. We believe that some of our findings are worthy of more in-depth discussion and may generate new questions to target future research in DIP.

In the latest international classification of IIPs from the ATS and the ERS from 2013 [1], DIP is one of the major IIPs and grouped as a smoking-associated IIP together with RB-ILD. Smoking is and remains the most strongly implicated risk factor for DIP. Nonetheless, our overview shows that a significant number of the cases (at least 19\%) were never smokers and 11\% were former smokers at time of diagnosis, indicating that smoking is not the sole cause of DIP. This is in contrast to RB-ILD, which is almost invariably associated with smoking $[76,82]$.

This leads to the question of whether DIP is justifiably classified amongst the smoking related IIPs. Other aetiologies for DIP have been suggested, mostly occupational exposures and less frequently auto-immune diseases [4]. However, causality cannot be established in many cases and frequently no other potential trigger is found at all, which renders cases truly idiopathic. Many still believe that RB-ILD and DIP comprise similar clinical entities along a spectrum but, given the important difference in exposure to smoking (with DIP not invariably being associated with smoking), this paradigm can be challenged for at least a proportion of patients with DIP. Also, DIP seems to have a more aggressive course of disease and there is no evidence that RB-ILD progresses to DIP [76]. It remains unknown whether smoking-related DIP, occupational exposure related DIP and idiopathic DIP have similar characteristics and responses to treatment. Interestingly, regarding prognosis, the pooled data in this review revealed that in the patients with both smoking history and outcomes reported, the (former) smokers had a better prognosis than the other patients with DIP. In addition, women appeared to have worse outcomes, although it should be noted that women were more frequently non-smokers.

In many cases of DIP, BAL is performed to exclude infectious disease; however, BAL including cell count appeared to be performed only rarely in the work-up for DIP. In the few cases for which BAL cell counts were available, the range of outcomes was very wide and findings such as large numbers of pigmented macrophages were not specific, as they can also be found in other conditions, for example RB-ILD. BAL alone is therefore not suitable for making a distinction between these entities. In some patients with DIP, very high eosinophilia counts were found in BAL [78]. Whether this would have prognostic implications, in analogy with idiopathic pulmonary fibrosis (IPF), remains unclear [83, 84].

Even though DIP is often present diffusely in the lung, the yield of transbronchial biopsies seems limited, if they are performed at all. Possible reasons can be sampling error and the fact that information regarding the distribution of abnormalities (i.e. predominance around the respiratory bronchioles versus a more uniform distribution) is necessary to distinguish between RB-ILD and DIP. Therefore, other methods of obtaining a tissue sample remain indicated and diagnosis is still best made using a (surgical) lung biopsy. Data on the value of cryobiopsy are not available at present, in particular because DIP patients are often grouped with RB-ILD patients in the literature on cryobiopsy [85]. However, the field of cryobiopsy is rapidly evolving and recent data show that cryobiopsy has a comparable diagnostic yield to surgical lung biopsy if performed in expert centres and combined with an MDT $[86,87]$. Future studies should reveal whether DIP can be reliably distinguished from RB-ILD using cryobiopsy.

In 1978, CARRINGTON et al. [70] compared DIP to usual interstitial pneumonia (UIP) and showed that DIP responded well to corticosteroids, with a good prognosis in contrast to patients with UIP. Generally, DIP is still considered to have a good prognosis, especially if smoking is discontinued early in the course of the disease. This view is also reflected in the current disease behaviour classification from the guideline, which states that most cases of DIP can at least be stabilised [1]. In addition, other reviews conclude that with treatment most patients remain stable or improve and that complete recovery is possible $[4,88]$. Survival 
rates of $90 \%$ at 10 years have been reported [78]; however, these prognostications are based on small numbers of patients. When considering prognosis more systematically, based on all published cases as we have done in the current review, a less optimistic image appears. Thus, based on the data on lung function testing, around $50 \%$ of patients improved; however, many did not improve and retained significant complaints and pulmonary dysfunction, or even deteriorated despite treatment. In the published cases more than one fourth of patients died or underwent lung transplantation despite treatment. In addition, at least $18 \%$ of cases experienced a relapse after treatment. The latter figure is most probably a notable underestimation, as follow-up was relatively short in many of the described cases. All of this indicates a less benign course of disease than is frequently suggested.

The first step in treatment of DIP is removal of the supposed culprit exposure, if present. The search for a potential culprit exposure should be done by an experienced team and should be very thorough. However, data on specific responses to smoking cessation or removal of another culprit exposure were not available. Nevertheless, it is our opinion that the removal of the suspected culprit exposure deserves explicit attention in patients with DIP, given the important link with smoking and other exposures and should always be attempted.

Generally, further treatment consists of corticosteroids with very diverse dosing or duration of treatment regimens having been reported. The evidence for a treatment effect is sparse. Looking at the series from CARRINGTON et al. [70], the course of disease was more favourable in treated patients (62\%) than in those without treatment $(22 \%)$. This finding and the individual effects reported in the cases imply a possible beneficial effect of steroid treatment for some patients, although reporting bias may play a role in these findings.

If deterioration occurred despite steroid treatment even more diverse treatment strategies were considered, such as more intensive immunosuppression with azathioprine or cyclophosphamide, or immunomodulatory therapies using antibiotics. Too little data are available to suggest an optimal treatment strategy or its expected effects. In selected cases, lung transplantation was the final treatment option; however, relapses after transplantation have been described [20,49]. Recently, nintedanib was found to significantly slow down lung function decline in patients with different forms of progressing fibrotic lung diseases, including DIP [89]. In the absence of other treatment options for the DIP subgroup with the worst prognosis, this may be a treatment option to consider.

There is ongoing debate as to whether the terminology of DIP is still valid or whether DIP belongs to the IIP group or not. We believe that there is sufficient data to support moving DIP from the IIP group to the group of diffuse parenchymal lung diseases of known cause [1]. With current knowledge DIP is, technically speaking, no longer the most suitable name for this disease; however, changing it will not do justice to the research done to date, will probably lead to confusion for patients, doctors and researchers and will delay further research projects. To advance the field of DIP research, a Delphi survey could form a basis for a statement initiative to come to uniform diagnostic criteria (in analogy with recently published work on hypersensitivity pneumonitis), allowing for the set-up of clinical trials and multinational registries in the coming years [90].

In conclusion, with this review we aimed to collect all published cases and case series to more precisely characterise DIP. We provide summarised estimates of clinical findings, exposures, and radiology and pathology features, as well as treatments and outcomes. These estimates are, compared to the available data from small individual series of patients, the most precise available to date. These results are affected to an unknown extent by publication bias and the sometimes limited quality of the reports. Nonetheless, we can conclude that DIP remains a rare disease, frequently but not always related to smoking or other exposures. Furthermore, in a reasonable subgroup of patients, DIP behaves as a progressive disease more often than generally thought, which in some cases is possibly associated with a different underlying aetiology.

Despite this review yielding interesting and novel information, many questions remain. International collaboration is needed to prospectively collect structured data for rare diseases such as DIP in shared registries. Only in that way will we be able to truly answer questions regarding aetiology, effects of removal of exposure, optimal treatment and outcomes. This will be pivotal to improving prevention, diagnosis and treatment of DIP.

Conflict of interest: M.E. Hellemons has nothing to disclose. C.C. Moor has nothing to disclose. J. von der Thüsen has nothing to disclose. M. Rossius has nothing to disclose. A. Odink has nothing to disclose. L.H. Thorgersen has nothing to disclose. J. Verschakelen has nothing to disclose. W. Wuyts reports grants from Roche and Boehringer-Ingelheim paid to his institution, outside the submitted work. M.S. Wijsenbeek reports grants and other fees from Hoffman-La Roche and Boehringer-Ingelheim, and other fees from Galapagos, outside the submitted work. E. Bendstrup reports grants, personal fees and non-financial support from Boehringer-Ingelheim and Roche, and personal fees from Novartis, outside the submitted work. 


\section{References}

1 Travis WD, Costabel U, Hansell DM, et al. An official American Thoracic Society/European Respiratory Society statement: update of the international multidisciplinary classification of the idiopathic interstitial pneumonias. Am J Respir Crit Care Med 2013; 188: 733-748.

2 Liebow AA, Steer A, Billingsley JG. Desquamative interstitial pneumonia. Am J Med 1965; 39: 369-404.

3 American Thoracic Society, European Respiratory Society. American Thoracic Society/European Respiratory Society international multidisciplinary consensus classification of the idiopathic interstitial pneumonias. Am J Respir Crit Care Med 2002; 165: 277-304.

4 Godbert B, Wissler MP, Vignaud JM. Desquamative interstitial pneumonia: an analytic review with an emphasis on aetiology. Eur Respir Rev 2013; 22: 117-123.

5 Park DW, Kim TH, Shon JW, et al. Near fatal desquamative interstitial pneumonia with bilateral recurrent tension pneumothorax. Sarcoidosis Vasc Diffuse Lung Dis 2015; 32: 167-171.

6 Lovrenski A, Eri Ž, Tegeltija D, et al. Desquamative interstitial pneumonia: a case report. Srp Arh Celok Lek 2014; 142: 602-606.

7 Nakazawa A, Hagiwara E, Harada S, et al. Surgically proven desquamative interstitial pneumonia induced by waterproofing spray. Intern Med 2014; 53: 2107-2110.

8 Kroll RR, Flood DA, Srigley J. Desquamative interstitial pneumonitis in a healthy non-smoker: a rare diagnosis. Can Respir J 2014; 21: 86-88.

9 Esmaeilbeigi F, Juvet S, Hwang D, et al. Desquamative interstitial pneumonitis and systemic lupus erythematosus. Can Respir J 2012; 19: 50-52.

10 Swartz JS, Chatterjee S, Parambil JG. Desquamative interstitial pneumonia as the initial manifestation of systemic sclerosis. J Clin Rheumatol 2010; 16: 284-286.

11 Ishii H, Iwata A, Sakamoto N, et al. Desquamative interstitial pneumonia (DIP) in a patient with rheumatoid arthritis: is DIP associated with autoimmune disorders? Intern Med 2009; 48: 827-830.

12 Calabrò E, Zompatori M, Poletti V, et al. Desquamative interstitial pneumonitis (DIP) occurring during treatment with pegylated interferon and ribavirin. Respir Med CME 2009; 2: 77-79.

13 Knyazhitskiy A. Beneficial response to macrolide antibiotic in a patient with desquamative interstitial pneumonia refractory to corticosteroid therapy. Chest 2008; 134: 185-187.

14 Arai $\mathrm{T}$, Inoue $\mathrm{Y}$, Hayashi $\mathrm{S}$, et al. Intractable desquamative interstitial pneumonia in a tattooed man. Intern Med 2006; 45: 1055-1058.

15 Sung SA, Ko GJ, Kim JY, et al. Desquamative interstitial pneumonia associated with concurrent cytomegalovirus and Aspergillus pneumonia in a renal transplant recipient. Nephrol Dial Transplant 2005; 20: 635-638.

16 Iskandar SB, McKinney LA, Shah L, et al. Desquamative interstitial pneumonia and hepatitis C virus infection: a rare association. South Med J 2004; 97: 890-893.

17 Behnia MM, Cummings OW. Desquamative interstitial pneumonia masquerading as acute life-threatening pulmonary embolism. Am J Crit Care 2004; 13: 199-201.

18 Kim KS, Kim YC, Park KO, et al. A case of completely resolved pneumatocoeles in desquamative interstitial pneumonia. Respirology 2003; 8: 389-395.

19 Gould TH, Buist MD, Meredith D, et al. Fulminant desquamative interstitial pneumonitis. Anaesth Intens Care 1998; 26: 677-679.

20 Verleden GM. Recurrence of desquamative interstitial pneumonia after lung transplantation. Am J Respir Crit Care Med 1998; 157: 1349-1350.

21 Matsuo K, Tada S, Kataoka M, et al. Spontaneous remission of desquamative interstitial pneumonia. Intern Med 1997; 36: 728-731.

22 Patel MB. Desquamative interstitial pneumonia: a case presentation. Md Med J 1993; 42: 1119-1122.

23 Chaudhary PK, Jain SK, Jain KP, et al. Desquamative interstitial pneumonia. J Assoc Physicians India 1993; 41: 303-305.

24 Usui Y, Takayama S, Nakuyama M, et al. Case report of desquamative interstitial pneumonia: documentation of preserved pulmonary function after twelve clinical relapses. Respiration 1992; 59: 112-115.

25 Flusser G, Gurman G, Zirkin H, et al. Desquamative interstitial pneumonitis causing acute respiratory failure, responsive only to immunosuppressants. Respiration 1991; 58: 324-326.

26 Vedal S, Welsh EV, Miller RR, et al. Desquamative interstitial pneumonia. Computed tomographic findings before and after treatment with corticosteroids. Chest 1988; 93: 215-217.

27 Lipworth B, Woodcock A, Addis B, et al. Late relapse of desquamative interstitial pneumonia. Am Rev Respir Dis 1987; 136: 1253-1255.

28 Herbert A, Sterling G, Abraham J, et al. Desquamative interstitial pneumonia in an aluminum welder. Hum Pathol 1982; 13: 694-699.

29 Goldstein JD, Godleski JJ, Herman PG. Desquamative interstitial pneumonitis associated with monomyelocytic leukemia. Chest 1982; 81: 321-325.

30 Hunter AM, Lamb D. Relapse of fibrosing alveolitis (desquamative interstitial pneumonia) after twelve years. Thorax 1979; 34: 677-679.

31 Sokolowski JW Jr, Harrer WV. Desquamative interstitial pneumonia associated with normal chest film. Postgrad Med 1979; 66: 135-136.

32 Broor SL, Kaur U, Datta BN, et al. Desquamative interstitial pneumonia. Indian J Chest Dis Allied Sci 1977; 19: 96-100.

33 Bone RC, Wolfe J, Sobonya RE. Desquamative interstitial pneumonia following chronic nitrofurantoin therapy. Chest 1976; 69: Suppl. 2, 296-297.

34 Sahn SA, Schwarz MI. Desquamative interstitial pneumonia with a normal chest radiograph. Br J Dis Chest 1974; 68: $228-234$.

35 Genereux GP, Merriman JE. Desquamative interstitial pneumonia: progression to the end stage lung and the unusual complication of alveolar cell carcinoma. Case report. J Can Assoc Radiol 1973; 24: 144-149.

36 Corrin B, Price AB. Electron microscopic studies in desquamative interstitial pneumonia associated with asbestos. Thorax 1972; 27: 324-331. 
37 Nicolaescu V, Leahu S, Teculescu D, et al. Desquamative interstitial pneumonia. Report of a case. Rev Roum Med Intern 1972; 9: 491-497.

38 Catlett JM. Desquamative interstitial pneumonia. A case report and review of the literature. J Kans Med Soc 1971; 72: 469-472.

39 Gould VE, Gleason TH, Winterscheid LC. Desquamative interstitial pneumonia. Chest 1971; 59: 349-352.

40 Tushan FS, Zawadzki ZA, Vassallo CL, et al. Serum IgA deficiency in a man with desquamative interstitial pneumonia. Am Rev Respir Dis 1971; 103: 264-268.

41 Farr GH, Harley RA, Hennigar GR. Desquamative interstitial pneumonia. An electron microscopic study. Am J Pathol 1970; 60: 347-370.

42 Stewart KR, Rona G, Lillie JB. A case of desquamative interstitial pneumonia. Can Med Assoc J 1970; 102: 736-739.

43 Ansari A, Buechner HA, Brown M. Desquamative interstitial pneumonia: report of a case and review of the literature. Dis Chest 1968; 53: 511-516.

44 Young RC Jr, Jackson MA, Bell HD. Desquamative interstitial pneumonia. Report of a case of a recently described entity. Med Ann Dist Columbia 1966; 35: 535-540.

45 Goldberg NM, Mostyn EM. Desquamative interstitial pneumonia: a brief review of the literature and a discussion of treatment with oxygen and corticosteroids. Dis Chest 1967; 52: 245-250.

46 Yamakawa H, Suido Y, Sadoyama S, et al. Desquamative interstitial pneumonia complicated with IgG4-related lung disease. Intern Med 2017; 56: 1553-1556.

47 Flores-Franco RA, Luevano-Flores E, Gaston-Ramirez C. Sirolimus-associated desquamative interstitial pneumonia. Respiration 2007; 74: 237-238.

48 Sigala I, Kalomenidis I, Malagari K, et al. Dry cough and dyspnoea rapidly increasing to respiratory failure in a male smoker. Eur Respir J 2005; 25: 1122-1125.

49 King MB, Jessurun J, Hertz MI. Recurrence of desquamative interstitial pneumonia after lung transplantation. Am J Respir Crit Care Med 1997; 156: 2003-2005.

50 Halpenny D, Suh J, Garofano S, et al. A 29-year-old man with nonproductive cough, exertional dyspnea, and chest discomfort. Chest 2015; 148: E80-E85.

51 Klocke RA, Augerson WS, Berman HH, et al. Desquamative interstitial pneumonia. A disease with a wide clinical spectrum. Ann Intern Med 1967; 66: 498-506.

52 Matsuo A, Matsumoto N, Kitamura A, et al. Desquamative interstitial pneumonia complicated by diffuse alveolar haemorrhage. Respirology Case Rep 2018; 6: e00291.

53 Otoshi R, Yamakawa H, Takemura T, et al. Anti-Ku antibody-positive desquamative interstitial pneumonia. Respir Med Case Rep 2019; 26: 115-117.

54 Pickell T, Donnelly J, Abi Fadel F. Smoking relapse causing an acute exacerbation of desquamative interstitial pneumonia with pleural effusions and mediastinal adenopathies. Case Rep Pulmonol 2018; 2018 : 8503694.

55 Freed JA, Miller A, Gordon RE, et al. Desquamative interstitial pneumonia associated with chrysotile asbestos fibres. Br I Ind Med 1991; 48: 332-337.

56 Ayvazian LF. Desquamative interstitial pneumonia. A systemic disease and precancerous lesion? J Med Soc N J 1974; 71: 115-119.

57 Ishiguro T, Takayanagi N, Kurashima K, et al. Desquamative interstitial pneumonia with a remarkable increase in the number of BAL eosinophils. Intern Med 2008; 47: 779-784.

58 Shortland JR, Darke CS, Crane WA. Electron microscopy of desquamative interstitial pneumonia. Thorax 1969; 24: $192-208$.

59 Goff AM, McNaryWF Jr, Gaensler EA. Desquamative interstitial pneumonia. Med Thorac 1967; 24: 317-329.

60 Brewer DB, Heath D, Asquith P. Electron microscopy of desquamative interstitial pneumonia. J Pathol 1969; 97: 317-323.

61 Medenica M, Medenica M. Desquamative interstitial pneumonia with clinical, radiological and histologic correlation. Radiol Case Rep 2019; 14: 505-509.

62 Cruz E, Rodriguez J, Lisboa C, et al. Desquamative alveolar disease (desquamative interstitial pneumonia): case report. Thorax 1969; 24: 186-191.

63 Ishii H, Oka H, Komiya K, et al. Clinical features of Japanese patients with desquamative interstitial pneumonia. Chest 2010; 138: 533A.

64 Prieto J, Sangro B, Beloqui O. Ribavirin in desquamative interstitial pneumonia. Chest 1988; 93: 446-447.

65 Lazarus DS, Mark EJ. Case 12-1993 - a 44-year-old man with pulmonary disease and proctitis. $N$ Engl J Med 1993; 328: 869-876.

66 Steinberg B. Differentiation of exfoliative broncho-alveolar disease from desquamative interstitial pneumonia. Am Rev Respir Dis 1966; 93: 568-577.

67 Gaensler EA, Goff AM, Prowse CM. Desquamative interstitial pneumonia. N Engl J Med 1966; 274: 113-128.

68 Tubbs RR, Benjamin SP, McCormack LJ. Desquamative interstitial pneumonitis - cellular phase of fibrosing alveolitis. Am J Clin Pathol 1977; 68: 105-105.

69 Valdivia E, Hensley G, Wu J. Morphology and pathogenesis of desquamative interstitial pneumonitis. Thorax 1977; 32: 7-18

70 Carrington CB, Gaensler EA, Coutu RE. Natural history and treated course of usual and desquamative interstitial pneumonia. N Engl J Med 1978; 298: 801-809.

71 Yousem SA, Colby TV, Gaensler EA. Respiratory bronchiolitis-associated interstitial lung disease and its relationship to desquamative interstitial pneumonia. Mayo Clin Proc 1989; 64: 1373-1380.

72 Hartman TE, Primack SL, Swensen SJ, et al. Desquamative interstitial pneumonia: thin-section CT findings in 22 patients. Radiology 1993; 187: 787-790.

73 Akira M, Yamamoto S, Hara H, et al. Serial computed tomographic evaluation in desquamative interstitial pneumonia. Thorax 1997; 52: 333-337.

74 Travis WD, Matsui K, Moss J, et al. Idiopathic nonspecific interstitial pneumonia: prognostic significance of cellular and fibrosing patterns: survival comparison with usual interstitial pneumonia and desquamative interstitial pneumonia. Am J Surg Pathol 2000; 24: 19-33. 
75 Ryu JH, Myers JL, Capizzi SA, et al. Desquamative interstitial pneumonia and respiratory bronchiolitis-associated interstitial lung disease. Chest 2005; 127: 178-184.

76 Craig PJ, Wells AU, Doffman S, et al. Desquamative interstitial pneumonia, respiratory bronchiolitis and their relationship to smoking. Histopathology 2004; 45: 275-282.

77 Baloira A, Xaubet A, Becerra ER, et al. [Desquamative interstitial pneumonia and respiratory bronchiolitis-associated interstitial lung disease: data from the Spanish patient registry]. Arch Bronconeumol 2008; 44: 499-503.

78 Kawabata Y, Takemura T, Hebisawa A, et al. Desquamative interstitial pneumonia may progress to lung fibrosis as characterized radiologically. Respirology 2012; 17: 1214-1221.

79 Veeraraghavan S, Latsi PI, Wells AU, et al. BAL findings in idiopathic nonspecific interstitial pneumonia and usual interstitial pneumonia. Eur Respir J 2003; 22: 239-244.

80 Margaritopoulos GA, Vasarmidi E, Jacob J, et al. Smoking and interstitial lung diseases. Eur Respir Rev 2015; 24: $428-435$.

81 Myers JL, Veal CF Jr, Shin MS, et al. Respiratory bronchiolitis causing interstitial lung disease. A clinicopathologic study of six cases. Am Rev Respir Dis 1987; 135: 880-884.

82 Fraig M, Shreesha U, Savici D, et al. Respiratory bronchiolitis: a clinicopathologic study in current smokers, ex-smokers, and never-smokers. Am J Surg Pathol 2002; 26: 647-653.

83 Peterson MW, Monick M, Hunninghake GW. Prognostic role of eosinophils in pulmonary fibrosis. Chest 1987; 92: 51-56.

84 Ravaglia C, Tomassetti S, Casoni G, et al. BAL findings in desquamative interstitial pneumonia (DIP) and other idiopathic interstitial pneumonia (IIP). Eur Respir J 2014; 44: Suppl. 58, P3743.

85 Ravaglia C, Bonifazi M, Wells AU, et al. Safety and diagnostic yield of transbronchial lung cryobiopsy in diffuse parenchymal lung diseases: a comparative study versus video-assisted thoracoscopic lung biopsy and a systematic review of the literature. Respiration 2016; 91: 215-227.

86 Ravaglia C, Wells AU, Tomassetti S, et al. Diagnostic yield and risk/benefit analysis of trans-bronchial lung cryobiopsy in diffuse parenchymal lung diseases: a large cohort of 699 patients. BMC Pulm Med 2019; 19: 16.

87 Troy LK, Grainge C, Corte TJ, et al. Diagnostic accuracy of transbronchial lung cryobiopsy for interstitial lung disease diagnosis (COLDICE): a prospective, comparative study. Lancet Respir Med 2020; 8: 171-181.

88 Diken ÖE, Sengül A, Beyan AC, et al. Desquamative interstitial pneumonia: risk factors, laboratory and bronchoalveolar lavage findings, radiological and histopathological examination, clinical features, treatment and prognosis (review). Exp Ther Med 2019; 17: 587-595.

89 Flaherty KR, Wells AU, Cottin V, et al. Nintedanib in progressive fibrosing interstitial lung diseases. $N$ Engl J Med 2019; 381: 1718-1727.

90 Morisset J, Johannson KA, Jones KD, et al. Identification of diagnostic criteria for chronic hypersensitivity pneumonitis: an international modified Delphi survey. Am J Respir Crit Care Med 2018; 197: 1036-1044. 